\title{
KARBON TERSIMPAN PADA KAWASAN SISTEM AGROFORESTRY DI REGISTER 39 DATAR SETUJU KPHL BATUTEGI KABUPATEN TANGGAMUS
}

\section{(STOCK CARBON AT AGROFORESTRY SYSTEM IN REGISTER 39 DATAR SETUJU KPHL BATUTEGI TANGGAMUS REGENCY)}

\author{
Dian Aprianto, Christine Wulandari, dan Niskan Walid Masruri \\ Jurusan Kehutanan, Fakultas Pertanian, Universitas Lampung \\ J1. Soemantri Brojonegoro No. 1, Bandar Lampung \\ Email: diiand28@yahoo.co.id \\ Phone: 085768769960
}

\begin{abstract}
ABSTRAK
Resort Datar Setuju merupakan salah satu dari enam resort yang ada di KPHL Batutegi tepatnya berada di Register 39. Kawasan ini dikelola dengan menerapkan sistem agroforestry. Penelitian bertujuan untuk mengetahui besarnya karbon tersimpan pada kawasan sistem agroforestry yang diaplikasikan oleh masyarakat di Register 39 Datar Setuju, dilaksanakan pada Bulan Maret 2015 di Register 39 Datar Setuju KPHL Batutegi Kabupaten Tanggamus. Selain untuk mengetahui besarnya karbon tersimpan, penelitian juga dilakukan untuk mengetahui vegetasi paling dominan. Metode Summed Dominance Ratio (SDR) dan Indeks Nilai Penting (INP) digunakan untuk mengetahui vegetasi yang paling dominan dan persamaan allometrik digunakan untuk mengetahui besar biomassa pohon dan nekromassa. Berdasarkan hasil penelitian, vegetasi fase pohon paling dominan adalah pohon cemara (Casuarina junghuniana) dengan nilai INP sebesar 109,91\%, fase tiang adalah dadap (Erythrina sp.) INP sebesar 300\%, fase pancang adalah kopi (Coffea arabica) INP sebesar $300 \%$, dan fase tumbuhan bawah adalah rumput teki (Cyperus rotundus) INP sebesar $200 \%$. Karbon tersimpan pada kawasan sistem agroforestry Register 39 Datar Setuju KPHL Batutegi pada HKm Sinar Harapan sebesar 123,33 ton/ha, HKm Bina Wana Jaya 1 sebesar 265,20 ton/ha, dan HKm Bina Wana Jaya 2 sebesar 146,20 ton/ha, sehingga nilai rata-rata karbon tersimpan di Register 39 Datar Setuju adalah 178,24 ton/ha.
\end{abstract}

Kata Kunci: karbon tersimpan, agroforestry

\section{ABSTRACT}

Datar Setuju Resort is the one of six resort located in Register 39 KPHL Batutegi. This area is managed by implementing agroforestry system Research aims to determine amount of stock carbon applied by publics in Register 39 Datar Setuju, held on March 2015 at Register 39 Datar Setuju KPHL Batutegi Tanggamus Regency. Beside to knowing amount of the stock carbon, this research also conducted to determine the dominant vegetation. Reseachers used Summed Dominance Ratio (SDR) and Importance Value Index (IVI) methods to determine the most dominant vegetations and used allometric equation to find out amount biomass and necromass of trees. Research results show that the most dominant vegetation on tree phase was cemara (Casuarina junghuniana) IVI large was 109,91\%, for pale phase was dadap (Erythrina sp.) IVI large was 300\%, for stake phase was kopi (Coffea arabica) IVI large was $300 \%$, and for seedling phase was rumput teki (Cyperus rotundus) IVI large was 200\%. Stock carbons at agroforestry system area Register 39 Datar Setuju KPHL Batutegi on HKm Sinar Harapan amount of 123,33 ton/ha, on HKm Bina Wana Jaya 1 amount of 265,20 ton/ha, and of HKm Bina Wana Jaya 2 amount of 146,20 ton/ha, average of stock carbon value at Register 39 Datar Setuju amount of 178,24 ton/ha.

Key words: stock carbon, agroforestry 


\title{
PENDAHULUAN
}

Hutan di Indonesia memiliki potensi yang sangat besar untuk dapat dimanfaatkan, namun kerusakan hutan di Indonesia terus meningkat setiap tahunnya. Salah satu penyebab kerusakan hutan yaitu karena adanya gangguan fungsi atmosfer untuk melindungi bumi dari pendinginan dan pemanasan yang berlebihan. Agar luas hutan tidak semakin berkurang akibat kerusakan hutan dan hutan mampu melakukan fungsinya yaitu sebagai penyimpan karbon, maka dilakukan optimalisasi penggunaan lahan. Sistem agroforestry merupakan pengoptimalisasian yang tepat untuk dapat dilakukan (Hairiah dan Rahayu, 2007). Jumlah karbon tersimpan dalam sistem agroforestry merupakan salah satu bentuk upaya penurunan konsentrasi gas rumah kaca (Natalia, 2014), khususnya penurunan karbondioksida $\left(\mathrm{CO}^{2}\right) \mathrm{di}$ atmosfer. Menurut Hairiah dan Rahayu (2007), agroforestry memiliki kemampuan menyerap dan menyimpan karbon lebih besar dibandingkan hutan tanaman. Kemampuan tersebut dipengaruhi oleh jumlah jenis tanam yang ditanam pada kawasan agroforestry, diameter vegetasi, dan juga sistem pemanenan yang dilakukan. Kawasan Register 39 Resort Datar Setuju merupakan bagian dari Kesatuan Pengelolaan Hutan Lindung (KPHL) Batutegi Kabupaten Tanggamus. Di wilayah tersebut terdapat kawasan sistem agroforestry yang dikelola oleh masyarakat setempat yang sebagian besar adalah petani. Jenis tanaman yang ditanam oleh petani di Register 39 Datar Setuju yaitu tanaman kehutanan dan tanaman semusim. Tanaman semusim yang ditanam yaitu kopi (Coffea arabica), lada (Piper nigrum), talas (Colocasia esculenta), sedangkan untuk tanaman kehutanan yang dikombinasikan pada lahan agroforestry yaitu kemiri (Aleurites moluccana), sonokeling (Dalbergia latifolia), mahoni (Swietenia macrophylla), serta jenis tanaman Multi Purpose Trees Species (MPTs) seperti durian (Durio zibethinus) dan randu (Ceiba pentandra). Tujuan dari penelitian ini adalah untuk mengetahui besarnya karbon tersimpan pada kawasan sistem agroforestry di Register 39 Datar Setuju KPHL Batutegi Kabupaten Tanggamus. Hasil penelitian ini diharapkan dapat memberikan informasi mengenai potensi karbon pada kawasan sistem agroforestry di Register 39 Datar Setuju Kabupaten Tanggamus dalam mendukung penurunan gas rumah kaca serta dijadikan sebagai refrensi untuk penelitian-penelitian selanjutnya.

\section{METODE PENELITIAN}

\section{Lokasi dan Waktu Penelitian}

Penelitian ini dilakukan pada bulan Maret 2015 bertempat di kawasan sistem agroforestry Register 39 Datar Setuju KPHL Batutegi Kabupaten Tanggamus (Gambar 1).

\begin{abstract}
Alat dan Bahan
Objek dalam penelitian ini adalah pohon (pohon hutan dan tanaman MPTs), pohon mati (nekromassa) baik yang masih berdiri maupun yang telah roboh, serta serasah di atas permukaan tanah yang ada di dalam petak contoh pengamatan pada lahan agroforestry di Register 39 Datar Setuju KPHL Batutegi. Alat yang digunakan dalam penelitian ini yaitu tongkat sepanjang 1,3 meter, meteran, christenhypsometer, tally sheet, spidol, parang, kantong plastik, oven timbangan digital, kamera, tali rapia dan tali tambang, serta alat tulis.
\end{abstract}




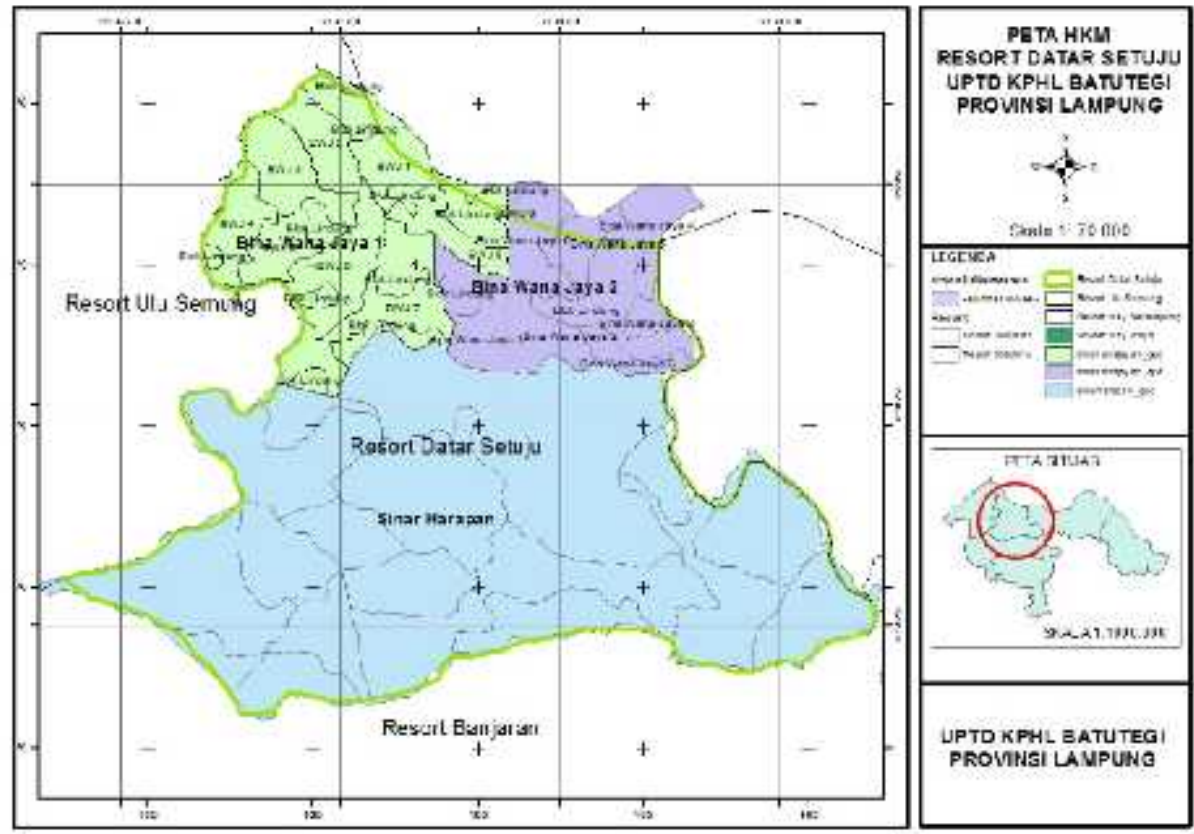

Gambar 1. Register 39 Datar Setuju KPHL Batutegi Kabupaten Tanggamus

\section{Metode Analisis Data}

a. Besarnya INP pada suatu vegetasi dapat dihitung dengan persamaan (Indriyanto, 2006):

$$
\begin{gathered}
\text { Kerapatan }(\mathrm{K})=\frac{\text { Jumlah individu suatu jenis }}{\text { luas seluruh petak contoh }} \\
\text { Kerapatan Relatif } \mathrm{KR}=\frac{\text { Kerapatan suatu jenis }}{\text { Kerapatan seluruh jenis }} \times 100 \% \\
\text { Frekuensi }(\mathrm{F})=\frac{\text { Jumlah petak ditemukannya suatu jenis }}{\text { Jumlah seluruh petak }} \\
\text { Frekuensi Relatif FR }=\frac{\text { Frekuensi suatu jenis }}{\text { Frekuensi seluruh jenis }} \times 100 \% \\
\text { Dominansi (D) }=\frac{\text { Luas basal area suatu spesies }}{\text { Luas seluruh petak contoh }} \\
\text { Dominansi Relatif DR }=\frac{\text { Dominansi suatu jenis }}{\text { Dominansi seluruh jenis }} \times 100 \%
\end{gathered}
$$

Berdasarkan persamaan tersebut, maka untuk menghitung besar INP suatu spesies untuk fase pohon, tiang, dan pancang yaitu:

$$
\mathrm{INP}=\mathrm{KR}+\mathrm{FR}+\mathrm{DR}
$$

Selanjutnya untuk menghitung besar INP fase tumbuhan bawah menggunakan perhitungan seperti berikut (Kainde et al., 2001):

$$
\mathrm{INP}=\mathrm{KR}+\mathrm{FR}
$$

b. Pendugaan biomassa pohon dan biomassa nekromassa (jika dikethui jenisnya) menggunakan persamaan allometrik, sedangkan pendugaan biomassa nekromassa yang tidak diketahui jenisnya menggunakan persamaan volume slindris.

c. Pendugaan biomassa serasah menggunakan rumus Biomass Expansion Factor (Brown, 1997). 
d. Selanjutnya pendugaan karbon tersimpan menggunakan metode menurut Intergovermental Panel on Climate Change (IPCC). Menurut IPCC (2006) fraksi karbon dari biomassa adalah 0,50 $(0,44-0,55)$ yang berarti bahwa $50 \%$ dari biomassa adalah karbon tersimpan. Besar karbon tersimpan dapat dihitung dengan :

Karbon tersimpan $=$ Biomassa $\times 0,5$

\section{HASIL DAN PEMBAHASAN}

Masyarakat Register 39 Datar Setuju KPHL Batutegi Kabupaten Tanggamus megelola lahan dengan menerapkan sistem agroforestry. Penggunaan lahan oleh masyarakat dengan menerapkan sistem agroforestry ini tersebar di setiap HKm. Penyusun agroforestry di kawasan tersebut terdiri dari tanaman kehutanan, tanaman MPTs, dan juga tanaman pertanian/perkebunan. Register 39 Datar Setuju ini terdiri dari tiga kelola Hutan Kemasyarakatan $(\mathrm{HKm})$ yang dibedakan berdasarkan luasan wilayahnya yaitu HKm Sinar Harapan, HKm Bina Wana Jaya 1, dan HKm Bina Wana Jaya 2 yang masing-masing HKm dihitung INP dan biomassanya.

\section{Indeks Nilai Penting (INP)}

Tujuan dilakukan perhitungan INP adalah untuk mengetahui jenis setiap fase tanaman yang mendominasi sistem agroforestry Register 39 Datar Setuju KPHL Batutegi. Berdasarkan hasil analisis vegetasi yang telah dilakukan, maka didapat bahwa pada kawasan sistem agroforestry Register 39 Datar Setuju KPHL Batutegi terdapat 18 jenis fase pohon, 8 jenis fase tiang, 4 jenis fase pancang, serta 6 jenis fase tumbuhan bawah. Dengan dilakukannya perhitungan INP, maka akan diketahui komposisi spesies dan struktur komunitas suatu wilayah khususnya di Register 39 Datar Setuju KPHL Batutegi. Hasil rekapitulasi komponen penyusun tanaman pada setiap HKm di Register 39 Datar Setuju dapat dilihat pada Tabel 1, Tabel 2, Tabel 3, dan Tabel 4.

Tabel 1. Rekapitulasi INP fase pohon pada masing-masing HKm di Register 39 Datar Setuju KPHL Batutegi.

\begin{tabular}{|c|c|c|c|c|c|}
\hline \multirow[t]{2}{*}{ No } & \multicolumn{2}{|c|}{ Jenis Tanaman } & \multicolumn{3}{|c|}{ Register 39 Datar Setuju } \\
\hline & Nama Daerah & Nama Latin & $\begin{array}{l}\text { HKm Sinar } \\
\text { Harapan }\end{array}$ & $\begin{array}{c}\text { HKm Bina } \\
\text { Wana Jaya } 1\end{array}$ & $\begin{array}{c}\text { HKm Bina } \\
\text { Wana Jaya } 2\end{array}$ \\
\hline 1. & Sonokeling & Dalbergia latifolia & 31,13 & - & - \\
\hline 2. & Mahoni & Swietenia machrophylla & 56,10 & - & - \\
\hline 3. & Karet & Havea braziliensis & 12,06 & - & - \\
\hline 4. & Wareng & Gmelina arborea & 7,06 & - & - \\
\hline 5. & Kemiri & Aleurites moluccana & 87,30 & - & - \\
\hline 6. & Medang & Litsea sp. & 29,65 & - & - \\
\hline 7. & Rambutan & Nephelium lappaceum & 6,09 & - & - \\
\hline 8. & Durian & Durio zibethinus & 15,38 & - & - \\
\hline 9. & Randu & Ceiba pentandra & 25,37 & 47,87 & - \\
\hline 10. & Cempaka & Michellia champacha & 11,51 & 50,19 & - \\
\hline 11. & Meranti & Shorea sp. & 5,63 & - & 78,52 \\
\hline 12. & Anggrung & Trema orientalis & 12,73 & - & - \\
\hline 13. & Bendo & Artocarpus elasticus & - & 74,07 & - \\
\hline 14. & Alpukat & Persea americana & - & 85,32 & - \\
\hline 15. & Nangka & Artocarpus integra & - & 42,56 & - \\
\hline 16. & Jengkol & Pithecellobium lobatum & - & - & 49,18 \\
\hline 17. & Cemara & Casuarina junghuniana & - & - & 109,91 \\
\hline 18. & Kayu Tabu & Crescentia pujeta & - & - & 62,39 \\
\hline \multicolumn{3}{|c|}{ Total } & 300,01 & 300,01 & 300,00 \\
\hline
\end{tabular}

Sumber: Data Primer, 2015 
Berdasarkan hasil analisis INP fase pohon di Register 39 Datar Setuju, diketahui bahwa pada lokasi tersebut terdapat 18 jenis pohon. Jenis pohon yang ditemukan di Register 39 Datar Setuju Kabupaten Tanggamus yaitu diantaranya 10 jenis pohon hutan dan 8 jenis tanaman MPTs. Jenis pohon terbanyak terdapat di HKm Sinar Harapan dengan 12 jenis pohon. Jenis pohon terbanyak kedua terdapat di HKm Bina Wana Jaya 1 dengan lima jenis pohon. Jenis pohon yang terdapat di HKm Bina Wana Jaya 2 terdapat empat jenis pohon.

Berdasarkan Tabel 1 dapat diketahui bahwa INP jenis pohon tertinggi adalah pohon cemara (Casuarina junghuniana) dengan besar INP yaitu 109,91\% yang berada di lokasi HKm Bina Wana Jaya 2. INP jenis pohon terendah yaitu pohon meranti (Shorea sp.) dengan nilai INP sebesar 5,63\% yang terdapat di lokasi HKm Sinar Harapan.

Tabel 2. Rekapitulasi INP fase tiang pada masing-masing HKm di Register 39 Datar Setuju KPHL Batutegi.

\begin{tabular}{llrrrr}
\hline \multirow{2}{*}{ No } & \multicolumn{2}{c}{ Jenis Tanaman } & \multicolumn{3}{c}{ Register 39 Datar Setuju } \\
\cline { 2 - 6 } & Nama Daerah & \multicolumn{1}{c}{ Nama Latin } & $\begin{array}{c}\text { HKm Sinar } \\
\text { Harapan }\end{array}$ & $\begin{array}{c}\text { HKm Bina } \\
\text { Wana Jaya 1 }\end{array}$ & $\begin{array}{c}\text { HKm Bina } \\
\text { Wana Jaya 2 }\end{array}$ \\
\hline 1. & Lamtoro & Leucaena leucocephala & 10,49 & - & - \\
2. & Mahoni & Swietenia machrophylla & 172,99 & - & - \\
3. & Karet & Havea braziliensis & 18,24 & 95,29 & - \\
4. & Medang & Litsea sp. & 64,07 & - & - \\
5. & Cempaka & Michelia champacha & 10,49 & 204,71 & - \\
6. & Petai & Parkia speciosa & 11,68 & - & - \\
7. & Durian & Durio zibethinus & 12,04 & - & - \\
8. & Dadap & Erythrina sp. & - & - & 300 \\
\hline \multicolumn{1}{c}{ Total } & & 300,00 & 300,00 & 300,00 \\
\hline
\end{tabular}

Sumber: Data Primer, 2015

Komposisi penyusun kawasan sistem agroforestry di Register 39 Datar Setuju untuk fase tiang terdiri dari 8 jenis tiang, yang terdiri dari 5 jenis tanaman kehutanan dan 3 jenis tanaman MPTS. Jenis tiang terbanyak ditemukan di HKm Sinar Harapan yaitu sebanyak 7 jenis tiang. Untuk lokasi HKm Bina Wana Jaya 1 terdapat dua jenis tiang. Satu jenis tiang di HKm Bina Wana Jaya satu, ditemukan juga di HKm Sinar Harapan. Pada HKm Bina Wana Jaya 2 hanya ditemukan satu jenis tiang tanaman kehutanan yaitu jenis dadap (Erythrina sp.).

Berdasarkan Tabel 2 mengenai INP fase tiang di kawasan sistem agroforestry Register 39 Datar Setuju, INP tertinggi diperoleh jenis dadap (Erythrina sp.) yang ditemukan di HKm Bina Wana Jaya 2 dengan besar INP 300\%. Hal yang membuat INP sebesar 300\% yaitu dikarenakan pada lokasi HKm Bina Wana Jaya 2 hanya ditemukan satu jenis tiang saja. INP terendah yaitu jenis lamtoro (Leucaena leucocephala) dan jenis cempaka (Michellia champacha) dengan INP sebesar 10,49\%.

Berdasarkan Tabel 3, dapat diketahui bahwa penyusun komposisi jenis pancang pada kawasan sistem agroforestry di KPHL Batutegi Kabupaten Tanggamus hanya terdiri dari empat tanaman jenis pancang. Keempat jenis tanaman tersebut adalah kopi (Coffea arabica), lada (Piper nigrum), talas (Colocasia esculenta), dan medang (Litsea sp.). Komposisi penyusun tanaman fase pancang pada kawasan sistem agroforestry ini terdiri satu jenis tanaman kehutanan dan tiga jenis tanaman pertanian. 
Tabel 3. Rekapitulasi fase pancang pada masing-masing HKm di Register 39 Datar Setuju KPHL Batutegi.

\begin{tabular}{lllrrr}
\hline \multirow{2}{*}{ No } & \multicolumn{2}{c}{ Jenis Tanaman } & \multicolumn{3}{c}{ Register 39 Datar Setuju } \\
\cline { 2 - 6 } & Nama Daerah & Nama Latin & HKm Sinar & HKm Bina & HKm Bina \\
Warapan & Wana Jaya 1 & Wana Jaya 2 \\
\hline 1. & Kopi & Coffea arabica & 267,71 & 300 & 300 \\
2. Lada & Piper nigrum & 11,59 & - & - \\
3. & Talas & Colocasia esculenta & 10,77 & - & - \\
4. & Medang & Litsea sp. & 9,94 & - & - \\
\hline \multicolumn{2}{l}{ Total } & & 300,01 & 300,00 & 300,00 \\
\hline
\end{tabular}

Sumber: Data Primer, 2015

Indeks Nilai Penting tertinggi untuk fase pancang yaitu jenis kopi (Coffea arabica) dengan INP sebesar 300\% yang ditemukan di HKm Bina Wana Jaya 1 dan HKm Bina Wana Jaya 2. INP terendah yaitu pada jenis medang (Litsea sp.) dengan INP sebesar 9,94\% yang ditemukan di HKm Sinar Harapan.

Tabel 4. Rekapitulasi fase tumbuhan bawah pada masing-masing HKm di Register 39 Datar Setuju KPHL Batutegi.

\begin{tabular}{lllrrr}
\hline \multirow{2}{*}{ No } & \multicolumn{2}{c}{ Jenis Tanaman } & \multicolumn{3}{c}{ Register 39 Datar Setuju } \\
\cline { 2 - 6 } & Nama Daerah & \multicolumn{1}{c}{ Nama Latin } & HKm Sinar & HKm Bina & HKm Bina \\
Harapan & Wana Jaya 1 & Wana Jaya 2 \\
\hline 1. & Singkong & Manihot esculenta & 6,16 & - & - \\
2. & Kopi & Coffea arabica & 6,16 & 29,11 & - \\
3. & Rumput teki & Cyperus rotundus & 141,28 & 155,78 & 200 \\
4. & Kentangan & Coleus atropurpureus & 26,88 & - & - \\
5. & Rumput gajah & Pennisetum purpureum & 5,77 & - & - \\
6. & Alang-alang & Imperata cylindrical & 13,76 & 15,11 & - \\
\hline \multicolumn{2}{l}{ Total } & & 200,01 & 200,00 & 200,00 \\
\hline
\end{tabular}

Sumber: Data Primer (2015)

Penyusun fase tumbuhan bawah di Register 39 Datar Setuju KPHL Batutegi terdapat enam jenis tumbuhan bawah yang ditemukan di HKm Sinar Harapan, tiga jenis ditemukan di HKm Bina Wana Jaya 1, dan satu jenis ditemukan di HKm Bina Wana Jaya 2 (Tabel 4). Setiap jenis tumbuhan bawah yang ditemukan di HKm Bina Wana Jaya 1 dan Bina Wana Jaya 2, ditemukan juga di HKm Sinar Harapan yang menjadi lokasi paling banyak ditemukan tumbuhan bawah.

Besar INP berdasarkan Tabel 4, dapat dilihat bahwa INP tertinggi yaitu pada rumput teki (Cyperus rotundus) yang ditemukan di HKm Bina Wana Jaya 2 dengan INP 200\%. Hal ini dikarenakan pada $\mathrm{HKm}$ tersebut hanya ditemukan satu jenis tumbuhan bawah. INP terendah yaitu pada jenis rumput gajah (Pennisetum purpureum) dengan besar nilai 5,77\% yang ditemukan di HKm Sinar Harapan.

\section{Karbon Tersimpan}

Karbon merupakan salah satu unsur utama pembentuk bahan organik termasuk makhluk hidup (Manuri et al., 2011). Karbon tersimpan pada tanaman, diperoleh dari hasil fotosintesis (Yuniawati et al., 2014). Hampir setengah dari organisme hidup merupakan karbon. Karenanya secara alami karbon banyak tersimpan di bumi baik di darat maupun di lautan dibandingkan jumlah karbon yang ada di atmosfer. Besarnya nilai karbon pada 
makhluk hidup, dapat diketahui melalui biomassa dari makhluk hidup tersebut. Hutan alami yang terdiri dari berbagai jenis tanaman, mampu menyerap karbon tersimpan lebih besar bila dibandingkan dengan lahan pertanian (Monde, 2009). Nilai karbon tersimpan pada tanaman, baik tanaman kehutanan, tanaman pertanian/perkebunan, maupun serasah dan nekromassa menunjukkan jumlah karbon atau gas rumah kaca di udara yang mampu diserap vegetasi melalui proses fotosintesis (Rahayu et al., 2004).

Pengukuran karbon pada kawasan sistem agroforestry di Register 39 Datar Setuju KPHL Batutegi, dilakukan di tiga lokasi HKm yang dapat dibedakan berdasarkan luasan kawasannya. Ketiga lokasi HKm tersebut dilakukan pengukuran biomassa karbon. Jenis fase tanaman pada setiap HKm telah diketahui berdasarkan perhitungan INP yang telah dilakukan. Hasil karbon tersimpan pada kawasan sistem agroforestry di Register 39 Datar Setuju KPHL Batutegi dapat dilihat pada Tabel 5.

Tabel 5. Jumlah Karbon Tersimpan pada masing-masing Hkm di Register 39 Datar Setuju KPHL Batutegi Kabupaten Tanggamus.

\begin{tabular}{|c|c|c|c|c|c|c|c|}
\hline \multirow{3}{*}{ No } & \multirow{3}{*}{$\begin{array}{l}\text { Lokasi } \\
\text { HKm }\end{array}$} & \multicolumn{4}{|c|}{ Biomassa (ton/ha) } & \multirow{3}{*}{ Total } & \multirow{3}{*}{$\begin{array}{l}\text { Karbon } \\
\text { Tersimpan } \\
\text { (ton/ha) }\end{array}$} \\
\hline & & \multicolumn{2}{|c|}{ Biomassa Pohon } & \multirow[b]{2}{*}{ Nekromassa } & \multirow[b]{2}{*}{ Serasah } & & \\
\hline & & $\begin{array}{c}\text { Tanaman } \\
\text { Kehutanan }\end{array}$ & $\begin{array}{l}\text { Tanaman } \\
\text { MPTs }\end{array}$ & & & & \\
\hline 1. & $\begin{array}{l}\text { Sinar } \\
\text { Harapan }\end{array}$ & 105,32 & 48,28 & 87,34 & 5,72 & 246,66 & 123,33 \\
\hline 2. & $\begin{array}{l}\text { Bina Wana } \\
\text { Jaya } 1\end{array}$ & 360,45 & 20,73 & 145,13 & 4,09 & 530,40 & 265,20 \\
\hline 3. & $\begin{array}{l}\text { Bina Wana } \\
\text { Jaya } 2\end{array}$ & 187,17 & 20,93 & 81,40 & 2,90 & 292,40 & 146,20 \\
\hline \multicolumn{2}{|c|}{ Jumlah } & 652,94 & 89,94 & 313,87 & 12,71 & $\begin{array}{r}1069,4 \\
6\end{array}$ & 534,73 \\
\hline \multicolumn{2}{|c|}{ Rata-Rata } & 217,65 & 29,98 & 104,62 & 4,24 & 356,49 & 178,24 \\
\hline \multicolumn{2}{|c|}{ Persentase (\%) } & 61,05 & 8,41 & 29,35 & 1,19 & & \\
\hline
\end{tabular}

Sumber: Data Primer (2015)

Hasil pendugaan karbon tersimpan atas permukaan tanah pada kawasan sistem agroforestry di Register 39 Datar Setuju KPHL Batutegi adalah 534,73 ton/ha dengan ratarata cadangan karbon yang dihasilkan adalah sebesar 178,24 ton/ha. Hasil tersebut didapat dari rata-rata total karbon tersimpan dari tiga HKm yang berada di Register 39 Datar Setuju. Jumlah besar karbon tersimpan pada HKm Sinar Harapan sebesar 123,33 ton/ha, HKm Bina Wana Jaya 1 sebesar 265,20 ton/ha, dan HKm Bina Wana Jaya 2 sebesar 146,20 ton/ha.

Menurut IPPC (2006), merekomendasikan bahwa angka stok karbon pada kategori lahan hutan primer, agroforestry, dan sekunder (forest land) adalah sebesar 138 ton/ha. Jika hasil karbon tersimpan pada kawasan hutan primer, agroforestry, maupun kawasan hutan sekunder sebesar 138 ton/ha, maka kawasan tersebut dikatakan baik. Apabila karbon tersimpan yang didapat pada kawasan hutan primer, agroforestry, dan sekunder dibawah dari 138 ton/ha maka stok karbon dikatakan kurang baik sehingga perlu dilakukan perawatan atau perbaikan pada kawasan tersebut.

Berdasarkan Tabel 5, dapat diketahui bahwa rata-rata besar karbon tersimpan pada kawasan sistem agroforestry di Register 39 Datar Setuju adalah sebesar 178,24 ton/ha. Mengacu pada IPCC (2006), diketahui bahwa cadangan karbon tersimpan atas permukaan tanah pada sistem agroforestry di Register 39 Datar Setuju KPHL Batutegi tergolong baik. Perbandingan jumlah karbon tersimpan pada setiap HKm di Register 39, dapat dilihat pada Gambar 3. 


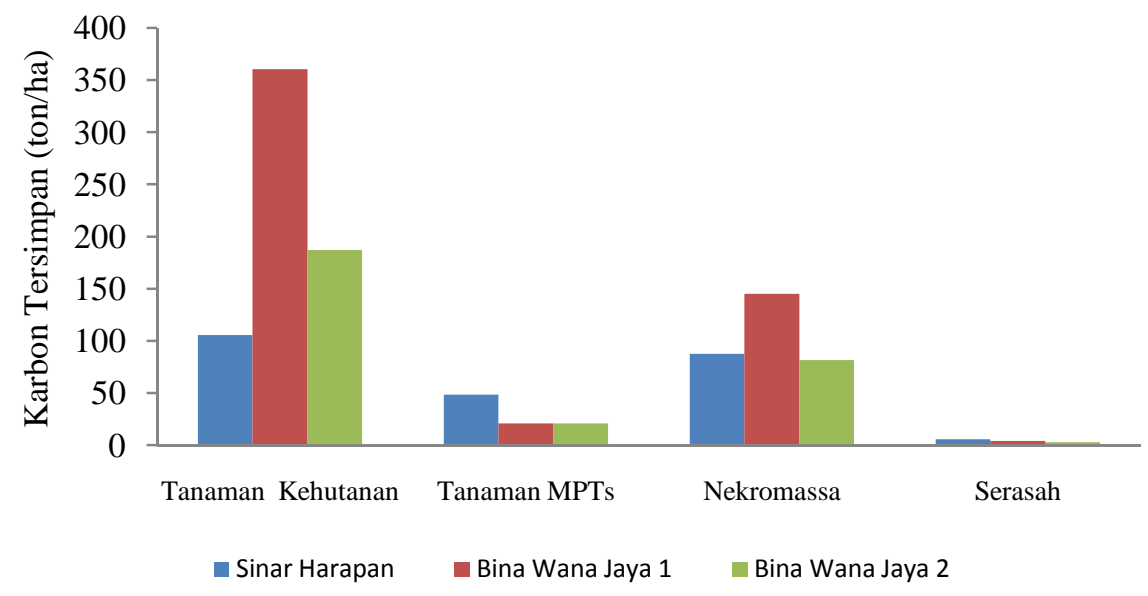

Gambar 3. Perbandingan karbon tersimpan pada masing-masing HKm di Register 39 Datar Setuju KPHL Batutegi Kabupaten Tanggamus.

Jumlah besar karbon tersimpan di Register 39 Datar Setuju KPHL Batutegi terdiri atas biomassa tanaman kehutanan yang memiliki besar biomassa 652,94 ton/ha, biomassa tanaman MPTs sebesar 89,94 ton/ha, biomassa nekromassa sebesar 313,87 ton/ha, serta biomassa serasah sebesar 12,71 ton/ha. Biomassa tanaman kehutanan (pohon hutan) di Register 39 Datar Setuju menyumbang sebesar 61,05\% dari total keseluruhan biomassa. Biomassa tanaman MPTs menyumbang sebesar 8,41\%, biomassa nekromassa sebesar $29,35 \%$, dan biomassa serasah hanya sebesar $1,19 \%$.

Biomassa pohon (tanaman kehutanan dan tanaman MPTs) merupakan penyumbang terbesar dalam biomassa atas permukaan yaitu sebesar 69,46\%. Hasil tersebut dikatakan cukup baik jika dibandingkan dengan hasil penelitian di Hutan Desa Aro Jambi, pada kawasan tersebut biomassa pohon menyumbang berkisaran antara 60,12\%-94,84\% dari total biomassa (Tresnawan et al., 2002).

Biomassa nekromassa dan biomassa serasah menyumbang sebesar 30,54\% dari total biomassa. Hasil tersebut kurang baik apabila dibandingkan dengan hasil penelitian sejenis yang dilakukan di hutan sekunder Sumberjaya Kabupaten Lampung Barat yaitu sebesar 8\% dari sumbangan biomassa nekromassa, biomassa serasah, dan biomassa tumbuhan bawah (Tresnawan et al., 2002). Karena jika pada suatu kawasan, biomassa nekromassa menyumbang cukup besar berarti kawasan tersebut didominasi oleh tanaman mati.

\section{KESIMPULAN}

Fase pohon paling dominan di Register 39 Datar Setuju KPHL Batutegi Kabupaten Tanggamus adalah pohon cemara (Casuarina junghuniana) dengan INP sebesar 109,91\%, untuk fase tiang paling dominan adalah jenis dadap (Erythrina sp.) dengan besar INP 300\%, untuk fase pancang adalah jenis kopi (Coffea arabica) dengan INP sebesar 300\%, serta fase semai paling dominan adalah jenis rumput teki (Cyperus rotundus) dengan besar INP 200\%.

Nilai rata-rata karbon tersimpan pada kawasan sistem agroforestry di Register 39 Datar Setuju KPHL Batutegi Kabupaten Tanggamus yaitu sebesar 178,24 ton/ha. Dengan rata-rata karbon tersimpan atas permukaan pada tanaman kehutanan sebesar 108,82 ton/ha $(61,05 \%)$, pada tanaman MPTs sebesar 14,99 ton/ha $(8,41 \%)$, pada nekromassa sebesar 52,31 ton/ha $(29,35 \%)$, dan pada serasah 2,12 ton/ha $(1,19 \%)$. 


\section{DAFTAR PUSTAKA}

Brown, S. 1997. Estimating Biomass and Biomass Change of Tropical Forest, a primer. FAO Forestry Paper 134. FAO Rome.

Hairiah, K., dan R. Subekti. 2007. Pengukuran Karbon Tersimpan di Berbagai Penggunaan Lahan. Buku. World Agroforestry Center-ICRAF. Bogor. 3-5 p.

Intergovermental Panel on Climate Change (IPCC). 2006. Intergovermental Panel on Climate Change Guidelones for National Greenhouse Gas Inventories, Prepared by the National Greenhouse Gas Inventories Programme, Eggleston H.S., Buendia L., Miwa K., Ngara T. And Tanabe K. (eds). Published: IGES, Japan.

Indriyanto. 2006. Ekologi Hutan. Buku. PT Bumi Aksara. Jakarta. 141-154 p.

Kainde, R.P., S.P. Ratag., J.S. Tasiri., dan D. Faryanti. 2011. Analisis vegetasi hutan lindung gunung tampa. Jurnal Eugenia. 17(3).

Manuri, S., C.A.S. Putra., dan A.D. Saputra. 2011. Tehnik Pendugaan Cadaangan Karbon Hutan. Buku. Merang REDD Pilot Project. Sumatera Selatan. 4 p.

Monde, A. 2009. Degradasi stok karbon (c) akibat alih guna lahan hutan menjadi lahan kakao di das nopu, sulawesi tengah. Jurnal Agroland. 16: 110-117.

Natalia, D. 2013. Potensi penyerapan karbon pada sistem agroforestri di desa pesawaran indah kecamatan padang cermin kabupaten pesawaran provinsi lampung. Skripsi. Universitas Lampung. Bandar Lampung. Tidak dipublikasikan. 41-49 p.

Natalia, D., S.B. Yuwono., dan R. Qurniaty. 2014. Potensi penyerapan karbon pada sistem agroforestri di desa pesawaran indah kecamatan padang cermin kabupaten pesawaran provinsi lampung. Jurnal Sylva Lestari. 2: 11 - 20.

Rahayu, S., B. Lusiana., dan M.V. Noordwijk. 2004. Pendugaan Cadangan Karbon di Atas Permukaan Tanah di Berbagai Sistem Penggunaan Lahan di Kabupaten Nunukan, Kalimantan Timur. Buku. Bogor: World Agroforestry Centre.

Tresnawan, H., dan U. Rosalina. 2002. Pendugaan biomassa di atas tanah di ekosistem hutan primer dan hutan bekas tebangan (studi kasus hutan dusun aro, jambi). Jurnal Manajemen Hutan Tropika. 8: 15-29.

Yuniawati, dan S. Suhartana. 2014. Potensi karbon pada limbah pemanenan kayu acacia crassicarpa. Jurnal Ilmu Lingkungan. 12: 21-31. 
Vol. 4 No. I, Januari 2016 (21-30)

Halaman ini sengaja dikosongkan 